\title{
Avaliação econômica por projeção financeira de um adensamento de erva-mate
}

\author{
Eraldo Antonio Bonfatti Júnior ${ }^{1}$, Elaine Cristina Lengowski² Pablo Machado $^{3}$ e Kauana Melissa Cunha Dickow ${ }^{4}$
}

\begin{abstract}
Resumo - A exploração de erva-mate é uma das atividades agrícolas mais antigas na região do Planalto Norte Catarinense. Além do vínculo cultural, representa fonte de renda e empregabilidade para os agricultores. O presente trabalho destina-se ao estudo da avaliação econômica de um adensamento aleatório de erva-mate em um plantio nativo. A produtividade do erval foi estimada em três sistemas de colheita: em sistema anual, em sistema bienal (Bienal 1) e em sistema intercalado, onde cada metade do erval é colhida a cada dois anos intercalados (Bienal 2). Para cada sistema de colheita foram calculados o payback, a razão receitas/custos, o custo médio de produção, o valor presente líquido (VPL), o valor anual equivalente (VAE), o valor presente líquido infinito (VPL $\infty$ ) e a taxa interna de retorno (TIR). Após processados todos os dados, o sistema anual foi claramente o que apresentou o payback mais curto, de 1,66 ano, mostrando que nesse sistema o retorno do investimento inicial será mais rápido, pois evita a perda natural de folhas. O sistema de colheita anual também apresentou melhor VPL e maior TIR, de 76\%, demonstrando melhor viabilidade econômica.
\end{abstract}

Termos para indexação: Produtos florestais não madeireiros; payback; VPL; TIR.

\section{Economic evaluation by financial projection of an densification of yerba mate}

Abstract - The exploitation of yerba mate is one of the oldest agricultural activities in the region of Planalto Norte Catarinense, besides the cultural bond represents a source of income and employability for farmers. The present work is aimed at the study of the economic evaluation of a yerba mate densification. The study herd is a random densification in a native plantation, done with the intention of increasing the productivity. Herb productivity was estimated in three harvesting systems: in an annual system, in a biennial system (Biennial 1) and in an intercalated system, where each half of the herd is harvested every two years intercalated (Biennial 2). For each collection system, the payback, the revenue/cost ratio, the average cost of production, the net present value (NPV), equivalent annual value (EAV), infinite net present value (NPV $\infty$ ) and the internal rate of return (IRR) were calculated. After processing all the data, the annual system was clearly the one with the shortest payback of 1.66 years showing that in this system the return on the initial investment will be faster, since it avoids the natural loss of leaves. The annual harvest system also presented better NPV and higher 76\% IRR, demonstrating better economic viability.

Index terms: Non-timber forest products; payback; NPV; IRR.

\section{Introdução}

A Floresta Ombrófila Mista possui remanescentes florestais nos estados do Rio Grande do Sul, Santa Catarina, Paraná, São Paulo e Minas Gerais, sendo um dos ecossistemas mais importantes do Brasil (LEITE \& KLEIN, 1990). Dentre as espécies florestais presentes na floresta ombrófila mista, destacam-se a Araucaria angustifolia, que também dá nome a essa tipologia florestal, e a llex paraguariensis (CUBAS, 2015) ou, em seu nome popular, erva-mate, que é de grande importância ambiental e socioeconômica para a Região Sul do Brasil, pois é seu principal produto florestal não madeireiro (FERMINO JÚNIOR \& FOCKINK, 2017).

A erva-mate possui importância social e econômica por ser uma cultura explorada predominantemente por pequenos produtores (SIGNOR et al., 2015), além da gerar empregos ao longo de sua cadeia produtiva (BONFATTI JÚNIOR et al., 2018), presente em aproximadamente 180 mil propriedades rurais, com cerca de 600 empresas e 700 mil empregos no Brasil (CHECHI et al., 2017).

A produção de erva-mate brasileira é crescente e vem sendo estimulada pelo bom preço do produto, associado a avanços tecnológicos para a atividade ervateira (JUNKEIRA et al., 2017). A Região Sul é a maior produtora de ervamate no Brasil. Em primeiro lugar, está o estado do Paraná, seguido pelo estado de Santa Cataria e em último pelo estado do Rio Grande do Sul. Além desses três estados, tem-se no Centro-Oeste o estado do Mato Grosso do Sul (JUNKEI-

Recebido em 25/7/2019. Aceito para publicação em 10/3/2020.

${ }^{1}$ Engenheiro Florestal, Msc., Doutorando em Engenharia Florestal, Universidade Federal do Paraná (UFPR), Avenida Pref. Lothário Meissner, 632, Jardim Botânico, Curitiba, PR 80210-170, Brasil, e-mail: bonfattieraldo@gmail.com.

${ }^{2}$ Engenheira Industrial Madeireira, Dra., Universidade Federal do Mato Grosso (UFMT), Rua Fernando Corrêa da Costa, 2367, Boa Esperança, Cuiabá, MT 78068-600, Brasil, e-mail: elainelengowski@gmail.com.

${ }^{3}$ Acadêmico de Engenharia Florestal, Universidade do Contestado (UnC), Rua Roberto Ehlke, 86, Centro, Canoinhas, SC CEP 89460-010, Brasil, e-mail: p.pablomachado@gmail.com.

${ }^{4}$ Engenheira Florestal, Dra., Universidade do Contestado (UnC), Rua Roberto Ehlke, 86, Centro, Canoinhas, SC CEP 89460-010, Brasil, e-mail: kauana@unc.br. 
RA et al. 2017), que tem uma produção muito pequena em relação aos outros estados e que vem diminuindo a cada ano (WOLF \& PEREIRA, 2015).

A análise econômica de um investimento envolve o uso de técnicas e critérios de análise que comparam os custos e as receitas inerentes ao projeto, visando decidir se este deve ou não ser implementado ou até mesmo modificado (REZENDE \& OLIVEIRA, 2013). Essas análises devem se basear no fluxo de caixa, quando o empreendimento já foi instalado, ou em projeções financeiras para projetos ainda não executados (SILVA et al., 2005; REZENDE \& OLIVEIRA, 2013). Portanto, o estudo de avaliação de investimentos se refere basicamente às decisões de aplicações de capital em projetos que prometem retorno por vários períodos consecutivos (ASSAF NETO, 2016).

A exploração da erva-mate é um meio de se manter os remanescentes de Floresta Ombrófila Mista e garantir renda aos agricultores detentores desses remanescentes. Diante disso o presente estudo teve como objetivo avaliar economicamente três sistemas de coIheita distintos de um adensamento de erva-mate.

\section{Material e métodos}

O estudo foi realizado no município de Canoinhas, no estado de Santa Catarina. O talhão estudado está localizado a uma latitude de $26^{\circ} 10^{\prime} 38^{\prime \prime} \mathrm{S}$, longitude de $050^{\circ} 23^{\prime} 24^{\prime \prime} \mathrm{W}$, altitude de 839 metros acima do nível do mar, e pertence à Fazenda Mendes localizada no bairro rural de Fartura. O erval de estudo se trata de um adensamento realizado em fevereiro de 2017, em um fragmento florestal nativo com área de 20,57 ha, feito com o intuito de aumentar a produtividade da área. Nesse erval não foi feita nenhuma prática silvicultural, portanto não houve práticas de conservação do solo, adubação ou controle de pragas. Tal ausência de um manejo adequado, apesar de não recomendada, é muito comum entre pequenos produtores.

$O$ adensamento foi feito de forma aleatória, buscando-se eliminar as clareiras da espécie, não tendo controle de quantas mudas foram plantadas e, tão pouco, a densidade de todas as árvores, plantadas e nativas. Portanto, para eliminar essa ausência de informação, foi realizado inventário florestal para determinar o número médio de árvores de erva-mate por hectare, utilizando como método de amostragem parcela quadrada de $20 \times 20 \mathrm{~m}\left(400 \mathrm{~m}^{2}\right)$, em processo de amostragem aleatório e com erro máximo admissível de $10 \%$ e nível de probabilidade fixado em $95 \%$.

Para realizar as estimativas de produção do erval os cálculos foram realizados utilizando o desempenho de produtividade descrito por EMBRAPA (1997), que preconiza que a produção inicia no primeiro ano após a implantação do empreendimento e aumenta até o oitavo ano, quando alcança a média de 6,3kg por árvore, que se mantém até por volta de 22 anos. A Figura 1 mostra a taxa de produtividade de uma árvore de erva-mate ao longo do tempo.

A produtividade do erval foi estimada em três possibilidades distintas de sistemas de colheita: o primeiro em que a partir do primeiro ano há colheita anualmente (ANUAL); um em que a partir do segundo ano a colheita é feita bienalmente (BIENAL 1); e um terceiro que contempla, a partir do primeiro ano, coIheita bienal das metades do erval em anos separados, logo cada metade é coIhida a cada dois anos (BIENAL 2).

A produção do erval por hectare foi

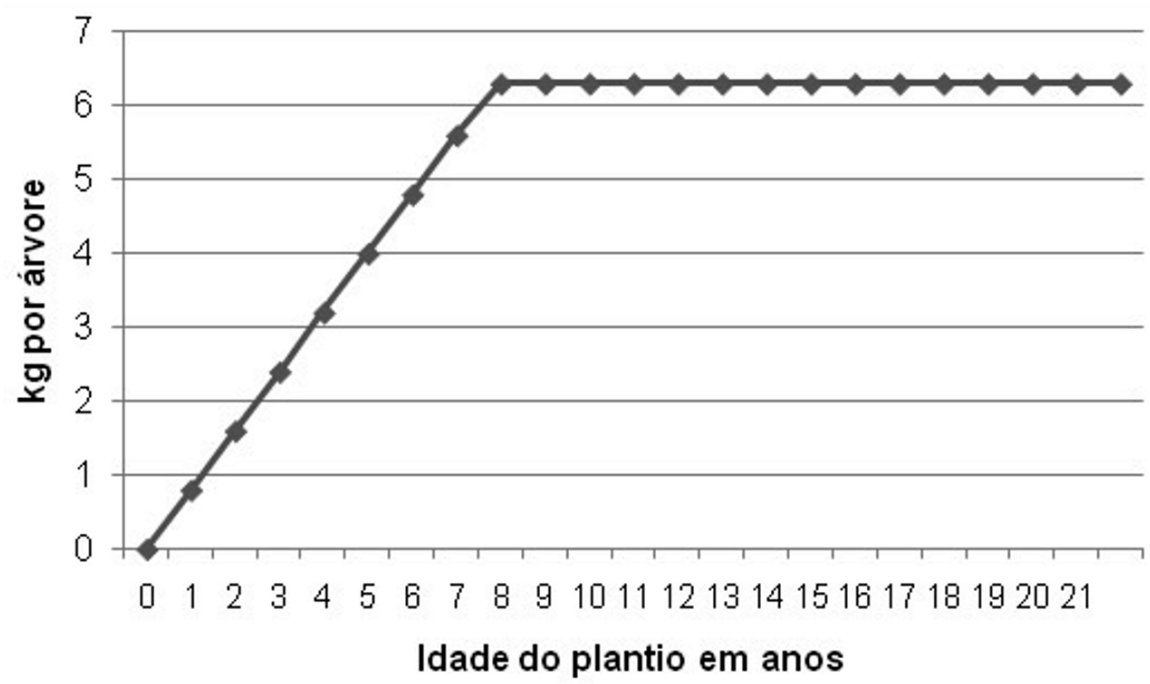

Figura 1 - Produtividade de uma árvore de erva-mate ao longo do tempo. Fonte: EMBRAPA (1997)

Figure 1 - Yerba mate tree productivity over time. Source: EMBRAPA (1997) 
SAF NETO, 2016) e consiste em verificar qual projeto apresenta menor tempo de retorno de capital, ou seja, o tempo necessário para que o somatório das receitas iguale ao somatório dos custos. $\mathrm{O}$ payback é a razão do capital inicial investido pelo resultado médio do fluxo de caixa (REZENDE \& OLIVEIRA, 2013).

Para realização da razão receita/custos foi dividido o somatório nominal das receitas que ocorrem durante a vida útil do projeto pelo somatório nominal dos custos. Dessa forma, quanto maior o valor da razão, mais interessante será a opção de investimento e, logicamente, razões menores que um são consideradas inviáveis economicamente (REZENDE \& OLIVEIRA, 2013).

O custo médio de produção faz referência ao custo de produção de cada unidade padrão produzida, sendo encontrado o cociente do somatório dos custos totais obtidos ao final do projeto pela produção total ao final do projeto (PASA et al., 2017). É melhor economicamente o investimento que apresentar o menor custo médio de produção (REZENDE \& OLIVEIRA, 2013).

Na elaboração ou avaliação de um investimento é necessária a definição da taxa de retorno exigida (ASSAF NETO, 2016). Para o referido trabalho foram utilizadas como taxas de descontos anuais de $2,5 \%, 6 \%, 7 \%, 8 \%$ e $10 \%$, sendo a primeira referente ao Pronaf Florestal (BANCO DO BRASIL, 2018).

O VPL consiste em trazer para a data zero, que é a data presente, todos os fluxos de caixa de um investimento e somá-los ao valor inicial, ou seja, todo o gasto que foi realizado para dar início ao projeto. O VPL é definido pelo valor atual dos benefícios menos o valor atual das despesas (SILVA et al., 2005; REZENDE \& OLIVEIRA, 2013). A Equação 1, a seguir, representa o cálculo do VPL:

$$
V P L=\sum_{j=0}^{n} R_{j}(1+i)^{-j}-\sum_{j=0}^{n} C_{j}(1+i)^{-j} \text { (Equação 1) }
$$

Equação1: VPL: valor presente líquido; $\mathrm{Rj}$ : valor atual das receitas; $\mathrm{Cj}$ : valor atual dos custos; i: taxa mínima de atratividade; j: período em que as receitas ou custos ocorrem; e n: número máximo de períodos.

No método do valor presente líquido, a taxa de atratividade é o percentual de desconto dos fluxos de caixa. Quando o valor presente das entradas menos o das saídas de caixa é positivo, há indicação técnica de aceitação do investimento. Em caso contrário, o investimento deve ser rejeitado (ASSAF NETO, 2016).

O Valor Anual Equivalente (VAE) é a parcela periódica relacionada ao pagamento de uma quantia igual ao VPL da opção de investimento em análise ao longo de sua vida útil (SILVA \& FONTES, 2005; PASA et al., 2017). De acordo com Silva e Fontes (2005), o VAE transforma o valor atual do projeto, ou seja, o VPL, em fluxo de receitas ou custos periódicos e contínuos, equivalentes ao valor atual, durante a vida útil do projeto.

A Equação 2 abaixo apresenta o cálculo do VAE:

$$
\mathrm{VAE}=\frac{V P L[1+i]^{\mathrm{t}}-1}{1-(1+\mathrm{i})^{-\mathrm{tn}}}
$$

(Equação 2)

Equação 2: VAE: valor anual equivalente; VPL: valor presente líquido; i: taxa mínima de atratividade; $t$ : número de períodos de capitalização; e n: número máximo de períodos.

O projeto será considerado economicamente viável se apresentar VAE positivo, indicando que os benefícios periódicos são maiores que os custos periódicos. Quanto à seleção de opções, deve ser escolhida a que apresentar maior VAE para determinada taxa de desconto (REZENDE \& OLIVEIRA, 2013).

O Valor Presente Líquido Infinito (VPL $\infty)$ considera a replicação de um projeto em um horizonte infinito (SILVA; FONTES, 2005).

A Equação 3, a seguir, apresenta o cálculo do VPL $\infty$ :

$$
\text { VPL } \infty=\frac{\operatorname{VPL}(1+i)^{t}}{(1+i)^{t}-1} \quad \text { (Equação 3) }
$$

Equação 3: VPL $\infty$ : valor presente líquido infinito; VPL: valor presente líquido; i: taxa mínima de atratividade; t: número de períodos de capitalização; e n: número máximo de períodos.

À semelhança do VPL, o projeto que apresenta o VPL $\infty$ positivo é economicamente viável, sendo considerado o melhor aquele que apresentar maior VPL $\infty$ (SILVA \& FONTES, 2005).

A Taxa Interna de Retorno (TIR) é a taxa de desconto que iguala o valor atual das receitas futuras ao valor atual dos custos futuros do projeto, constituindo uma medida relativa que reflete o aumento no valor do investimento ao longo do tempo com base nos recursos requeridos para produzir o fluxo de receitas. O projeto será financeiramente viável quando a TIR for maior que a taxa mínima de atratividade (REZENDE \& OLIVEIRA, 2013). Devido a sua simplicidade e aplicabilidade, a TIR talvez seja a técnica mais utilizada para avaliação sobre alternativas de investimento (ASSAF NETO, 2016).

A Equação 4 representa o cálculo da TIR:

$$
\sum_{j=0}^{n} R_{j}(1+T I R)^{-i}-\sum_{j=0}^{n} C_{j}(1+T I R)^{-j}=0 \text { (Equação 4) }
$$

Equação 1: TIR: taxa interna de retorno; $\mathrm{Rj}$ : valor atual das receitas; $\mathrm{Cj}$ : valor atual dos custos; j: período em que as receitas ou custos ocorrem e $n$ : número máximo de períodos.

\section{Resultados e discussão}

O inventário florestal com 33 parcelas amostradas, intensidade amostral de $6,41 \%$, mostrou erro relativo de $\pm 9,84 \%$, ou seja, abaixo do erro máximo admissível previamente estipulado de $10 \%$. O valor médio de árvores por parcela encontrado $\frac{f_{\mathcal{X}}}{\mathrm{i}}$ de 72 árvores (IC $=[64,72$ árvores $\leq \mathrm{X} \leq 78,85$ árvores $]$ $=95 \%$ ), expandindo-se esse valor, temse densidade média de 1798 árvores de erva-mate por hectare.

A Tabela 1 mostra os resultados da estimativa da produtividade considerando a densidade de árvores por hectare encontrada pelo inventário florestal definitivo e a produtividade por árvore de acordo com Embrapa (1997) para os três sistemas de colheita avaliados, sendo descontado $25 \%$ nos sistemas bienais de colheita.

Pode-se observar que o desconto oriundo da queda natural das folhas causou considerável redução da produtividade nos sistemas bienais de colheitas.

A Tabela 2 mostra os custos envolvidos no investimento, considerando o custo de implantação, $\mathrm{R} \$ 3327,01$ por hectare, e os custos de colheita.

A Tabela 3 mostra o fluxo de caixa de cada sistema de colheita em um hectare de adensamento.

A Tabela 4 mostra os valores do payback, em anos, da razão receita custo e do custo médio de produção de um quilograma de erva-mate nos três sistemas 
Tabela 1. Estimativa de produção ao longo do tempo de acordo com o sistema de colheita Table 1. Estimated production over time according to the harvesting system

\begin{tabular}{|c|c|c|c|}
\hline \multirow{2}{*}{ Anos } & \multicolumn{3}{|c|}{$\mathrm{kg} \cdot \mathrm{ano}^{-1}$} \\
\hline & Anual & Bienal 1 & Bienal 2 \\
\hline 0 & 0 & 0 & 0 \\
\hline 1 & 1438 & 0 & 719 \\
\hline 2 & 2877 & 3236 & 1079 \\
\hline 3 & 4315 & 0 & 1618 \\
\hline 4 & 5754 & 7552 & 2158 \\
\hline 5 & 7192 & 0 & 2697 \\
\hline 6 & 8630 & 11867 & 3236 \\
\hline 7 & 10069 & 0 & 3776 \\
\hline 8 & 11327 & 16047 & 4248 \\
\hline 9 & 11327 & 0 & 4248 \\
\hline 10 & 11327 & 16991 & 4248 \\
\hline 11 & 11327 & 0 & 4248 \\
\hline 12 & 11327 & 16991 & 4248 \\
\hline 13 & 11327 & 0 & 4248 \\
\hline 14 & 11327 & 16991 & 4248 \\
\hline 15 & 11327 & 0 & 4248 \\
\hline 16 & 11327 & 16991 & 4248 \\
\hline 17 & 11327 & 0 & 4248 \\
\hline 18 & 11327 & 16991 & 4248 \\
\hline 19 & 11327 & 0 & 4248 \\
\hline 20 & 11327 & 16991 & 4248 \\
\hline 21 & 11327 & 0 & 4248 \\
\hline 22 & 11327 & 16991 & 9911 \\
\hline Total & 210186 & 157640 & 84663 \\
\hline
\end{tabular}

Tabela 2. Custo envolvidos no adensamento de erva-mate Table 2. Cost involved in the density of yerba mate

\begin{tabular}{c|cc}
\hline Ano & Atividade & Valor \\
\hline 0 & $\begin{array}{c}\text { Aquisição } \\
\text { das mudas }\end{array}$ & $\mathrm{R} \$ 2916,87 / \mathrm{ha}$ \\
\hline 0 & $\begin{array}{c}\text { Preparo do solo para } \\
\text { plantio }\end{array}$ & $\mathrm{R} \$ 410,14 / \mathrm{ha}$ \\
Anos de colheita & Roçada pré-colheita & $\mathrm{R} \$ 170,60 / \mathrm{ha}$
\end{tabular}

Anos de colheita

Custo da colheita

$\mathrm{R} \$ 0,18 / \mathrm{kg}$ de colheita.

O sistema de colheita anual foi claramente o que apresentou payback mais curto, mostrando que nesse sistema o investimento inicial retornará mais rapidamente, pois remuneração acontece neste caso antes do que nos outros dois sistemas. Entre o sistema Bienal 1 e Bienal 2 o payback acontece por volta de três anos em ambos.

Já, considerando a razão receita/ custo, o sistema de colheita mais interessante economicamente é o Bienal 1 , que apresentou melhor valor, pois o denominador - neste caso, os custos -, foi menor. Apesar da diferença dos resultados, todos os sistemas de colheitas apresentaram razão receita/custo alta.

Os custos de produção em todos os sistemas foram próximos, sendo a maneira mais barata de se produzir ervamate oriunda do sistema Bienal 1, seguido pelo sistema Anual e por último o sistema Bienal 2. Pode se explicar esse fato porque no sistema Bienal 1 não há custos de roçada pré-colheita todos os anos.

A Tabela 5 mostra os valores de remuneração do capital investido nos três sistemas de colheita nas diferentes taxas de descontos anuais empregadas.

Tanto o VPL, VAE e VPL $\infty$ apontaram que em todas as taxas de desconto o sistema de colheita de melhor desempenho foi o Anual. Todos os sistemas de colheita foram sensíveis às taxas, sendo possível verificar quedas nos critérios de avaliação com o aumento destas. Contudo, nenhum cenário apresentou situação inviável economicamente, ou seja, não foram encontrados critérios de avaliações nulos ou negativos. Vale ressaltar a importância de programas de financiamento sociais promovidos pelo governo, uma vez que o presente estudo indica que a taxa de juros aplicada pelo Pronaf Florestal é a que dá condições de melhor rendimento do investimento.

A Tabela 6 mostra a TIR encontrada para os três sistemas de colheitas.

A TIR é uma taxa intrínseca ao projeto e independe da taxa mínima de atratividade, de acordo com Rezende \& Oliveira (2013) e pode ser interpretada como a taxa média de crescimento de um investimento. Diante disso o sistema Anual de colheita é o melhor, pois 
Tabela 3. Fluxo de caixa em $\mathrm{R} \$(\mathrm{BRL})$ para os três sistemas de colheita em um hectare

Table 3. Cash flow in $R \$$ (BRL) for the three harvest systems in one hectare

\begin{tabular}{|c|c|c|c|c|c|c|c|c|c|}
\hline \multirow{3}{*}{ Anos } & \multicolumn{9}{|c|}{ Sistemas de Colheita } \\
\hline & \multicolumn{3}{|c|}{ Anual } & \multicolumn{3}{|c|}{ Bienal 1} & \multicolumn{3}{|c|}{ Bienal 2} \\
\hline & Custos & Receitas & Líquido & Custos & Receitas & Líquido & Custos & Receitas & Líquido \\
\hline 0 & -3327 & 0 & -3327 & -3327 & 0 & -3327 & -3327 & 0 & -3327 \\
\hline 1 & -430 & 1438 & 1009 & 0 & 0 & 0 & -215 & 719 & 504 \\
\hline 2 & -688 & 2877 & 2188 & -753 & 3236 & 2483 & -279 & 1079 & 799 \\
\hline 3 & -947 & 4315 & 3368 & 0 & 0 & 0 & -377 & 1618 & 1242 \\
\hline 4 & -1206 & 5754 & 4547 & -1530 & 7552 & 6022 & -474 & 2158 & 1684 \\
\hline 5 & -1465 & 7192 & 5727 & 0 & 0 & 0 & -571 & 2697 & 2126 \\
\hline 6 & -1724 & 8630 & 6906 & -2307 & 11867 & 9560 & -668 & 3236 & 2569 \\
\hline 7 & -1983 & 10069 & 8086 & 0 & 0 & 0 & -765 & 3776 & 3011 \\
\hline 8 & -2210 & 11327 & 9118 & -3059 & 16047 & 12988 & -850 & 4248 & 3398 \\
\hline 9 & -2210 & 11327 & 9118 & 0 & 0 & 0 & -850 & 4248 & 3398 \\
\hline 10 & -2210 & 11327 & 9118 & -3229 & 16991 & 13762 & -850 & 4248 & 3398 \\
\hline 11 & -2210 & 11327 & 9118 & 0 & 0 & 0 & -850 & 4248 & 3398 \\
\hline 12 & -2210 & 11327 & 9118 & -3229 & 16991 & 13762 & -850 & 4248 & 3398 \\
\hline 13 & -2210 & 11327 & 9118 & 0 & 0 & 0 & -850 & 4248 & 3398 \\
\hline 14 & -2210 & 11327 & 9118 & -3229 & 16991 & 13762 & -850 & 4248 & 3398 \\
\hline 15 & -2210 & 11327 & 9118 & 0 & 0 & 0 & -850 & 4248 & 3398 \\
\hline 16 & -2210 & 11327 & 9118 & -3229 & 16991 & 13762 & -850 & 4248 & 3398 \\
\hline 17 & -2210 & 11327 & 9118 & 0 & 0 & 0 & -850 & 4248 & 3398 \\
\hline 18 & -2210 & 11327 & 9118 & -3229 & 16991 & 13762 & -850 & 4248 & 3398 \\
\hline 19 & -2210 & 11327 & 9118 & 0 & 0 & 0 & -850 & 4248 & 3398 \\
\hline 20 & -2210 & 11327 & 9118 & -3229 & 16991 & 13762 & -850 & 4248 & 3398 \\
\hline 21 & -2210 & 11327 & 9118 & 0 & 0 & 0 & -850 & 4248 & 3398 \\
\hline 22 & -2210 & 11327 & 9118 & -1955 & 16991 & 15036 & -1955 & 9911 & 7957 \\
\hline
\end{tabular}

Tabela 4. Payback, razão receita/custo e custo médio de produção para os três sistemas de colheita analisados

Table 4. Payback, revenue/cost ratio and average cost of production for the three harvest systems analyzed

\begin{tabular}{c|c|c|c|}
\hline $\begin{array}{c}\text { Sistema de } \\
\text { Colheita }\end{array}$ & Payback, anos & Receita/custo & $\begin{array}{c}\text { Custo médio de } \\
\text { produção, R\$/kg }\end{array}$ \\
\hline Anual & 1,66 & 4,68 & 0,21 \\
\hline Bienal 1 & 3,00 & 4,88 & 0,20 \\
\hline Bienal 2 & 2,95 & 4,12 & 0,24 \\
\hline
\end{tabular}

apresenta a maior TIR, seguido pelo sistema Bienal 1 e Bienal 2. Ainda sobre esse parâmetro, um projeto é considerado viável economicamente quando sua TIR for superior a taxa de desconto.

\section{Conclusão}

Nenhum sistema de colheita é inviável economicamente.

O sistema anual de colheita, além de 
Tabela 5. Rendimento esperado em R\$ (BRL) dos três sistemas de colheita pelo VPL, VAE e VPL $\infty$ considerando as diferentes taxas de descontos

Table 5. Expected yield in RS (BRL) of the three harvesting systems by NPV, EAA and VPL $\infty$ considering the different discount rates

\begin{tabular}{ccccccc}
\hline \multirow{2}{*}{$\begin{array}{c}\text { Critério de } \\
\text { Avaliação }\end{array}$} & $\begin{array}{c}\text { Sistema de } \\
\text { colheita }\end{array}$ & $\mathbf{2 , 5 \%}$ & $\mathbf{6 \%}$ & $\mathbf{7 \%}$ & $\mathbf{8 \%}$ & $\mathbf{1 0 \%}$ \\
\cline { 3 - 7 } & Anual & 119779 & 79422 & 71182 & 64005 & 52227 \\
\hline \multirow{2}{*}{ VPL, R\$/ha } & Bienal 1 & 89346 & 57855 & 51493 & 45974 & 36972 \\
& Bienal 2 & 45272 & 28851 & 25545 & 22680 & 18017 \\
\hline \multirow{2}{*}{ VAE, R\$/ha } & Anual & 292917 & 116522 & 93239 & 84705 & 65494 \\
& Bienal 1 & 218495 & 84880 & 67211 & 60842 & 46363 \\
\hline \multirow{2}{*}{$\begin{array}{c}\text { VPL } \infty \text {, R\$ / } \\
\text { ha }\end{array}$} & Bienal 2 & 110711 & 42327 & 33250 & 30014 & 22588 \\
\hline & Anual & 285775 & 109927 & 87140 & 78432 & 59541 \\
\hline & Bienal 1 & 213168 & 80077 & 62815 & 56337 & 42149 \\
\hline
\end{tabular}

Tabela 6. TIR para os três sistemas de colheita analisados

Table 6. IRR for the three analyzed harvesting systems

\begin{tabular}{c|c}
\hline Sistema de Colheita & TIR \\
\hline Anual & $76 \%$ \\
\hline Bienal 1 & $56 \%$ \\
Bienal 2 & $41 \%$ \\
\hline
\end{tabular}

oferecer remuneração com periodicidade mais curta, evita a perda natural de folhas. Esses dois fatores refletiram em maior viabilidade econômica quando comparados com os outros dois sistemas.

\section{Agradecimentos}

Os autores agradecem os proprietários da Fazenda Mendes em Canoinhas, SC, por disponibilizar as informações financeiras referentes ao adensamento de erva-mate, objeto deste estudo.

\section{Referências}

ASSAF NETO, A. Matemática financeira e suas aplicações. São Paulo, SP: Atlas, 2016. $304 p$.

BANCO DO BRASIL. Pronaf Florestal. Disponível em: http://encurtador.com.br/bnJZ5. Acesso em: 25 maio. 2019.
BONFATTI JUNIOR, E.A.; LENGOWSKI, E.C.; LUDKA JÚNIOR, A. Mapeamento do processo produtivo de erva-mate. Revista Internacional de Ciências, Rio de Janeiro, v.8, n.1, p.82-98, 2018. DOI: http://dx.doi. org/10.12957/ric.2018.32500.

CARPANEZZI, A.A.; CARDOZO, A.; VALAIO, I.F.M.; GRAÇA, M.E.C.; IEDE, E.T.; HIGA, R.C.V. Queda anormal de folhas de erva-mate (Ilex paraguariensis). In: Seminário sobre Atualidades e Perspectivas Florestais, 1983, Curitiba. Anais[...] Curitiba, 1983. p.141-145.

CHECHI, L.A.; SCHULTZ; G.; FERRPNATTO, E.M.O.; MONTAGNER, J.M. Ativos territoriais e desenvolvimento: estudo da articulação pela indicação geográfica da erva-mate no polo ervateiro Alto Taquari - RS. Estratégia e Desenvolvimento, Santana do Livramento, v.1, n.1, p.16-34, 2017.

CUBAS, R. Restabelecimento de Araucária angustifólia e Ocotea porosa após sete décadas de exploração florestal. 2015. 120f. Tese (Doutorado em Engenharia Florestal) - Centro de Ciências Rurais, Universidade Federal de Santa Maria, Santa Maria, 2015.

EMBRAPA - EMPRESA BRASILEIRA DE PESQUISAS AGROPECUÁRIAS. Rentabilidade econômica comparativa entre plantios florestais e sistemas agroflorestais com erva-mate, eucalipto e pínus e as culturas do feijão, milho, soja e trigo. Colombo, PR: EMBRAPA, 1997. 35p

FERMINO JÚNIOR, P.C.P.; FOCKINK, G.D. Anatomia foliar de plantas jovens de erva-mate (Ilex paraguariensis A. St. Hill.) sob diferentes níveis de sombreamento. Scientia Agra- ria Paranaensis, Marechal Cândido Rondon, v.16, n.3, p.335-341, jul./set., 2017. DOI: http://dx.doi.org/10.18188/1983-1471/sap. v16n3p335-341.

JUNKEIRA, A.A.; BASSO, V.M.; SOUZA, N.D. Evolução da extração vegetal de erva-mate no período de 2004 a 2015. In: I Semana de Aperfeiçoamento em Engenharia Florestal, 2017, Curitiba. Anais[...] Curitiba, 2017. p.306-310.

LEITE, P.F.; KLEIN, R.M. Vegetação. In: IBGE. Geografia do Brasil: Região Sul. Rio de Janeiro: IBGE, 1990. p.113-150.

PASA, D.L.; LAUREANO, F.; FARIAS, J.A.; NOLASCO, B.G. Análise econômica de plantios florestais na agricultura familiar da região Sul. Revista de Economia e Agronegócio, Viçosa, v. 15, n. 2, p. 275-293, jun./dez. 2017. Disponível em: https://doi.org/10.25070/ rea.v15i2.469. Acesso em: 25 maio. 2019.

RAKOCEVIC, M.; MEDRADO, M.J.S.; LUCAMBIO, F.; VALDUGA, T.A. Ritmicidade de emissão e de queda de folhas e as suas consequências no manejo da erva-mate. In: Congreso Sudamericano de la Yerba Mate., 2006, Posadas. Anais[...] Posadas, 2006. P. 250-256.

REZENDE, J.L.P.; OLIVEIRA, A.D. Análise econômica de projetos florestais. 3. ed. Viçosa: UFV, 2013. 385p.

SIGNOR, P.; GOMES, G.S.; WATZLAWICK, L.F. Produção de erva-mate e conservação de Floresta com Araucária. Pesquisa Florestal Brasileira, Colombo, v. 35, n. 83, p. 199-208, jul./set. 2015. DOI: http://dx.doi. org/10.4336/2015.pfb.35.83.898.

SILVA, M.L.; JACOVINE, L.A.G.; VALVERDE, S.R. Economia florestal. 2. ed. Viçosa: UFV, 2005. 178p.

SILVA, M.L.; FONTES, A.A. Discussão sobre os critérios de avaliação econômica: valor presente líquido (VPL), valor anual equivalente (VAE) e valor esperado da terra. Revista Árvore, Viçosa, v. 26, n. 6, p. 931-936, nov./ dec. 2005.

WOLF,R.; PEREIRA, W.G. Análise econômica da evolução histórica da erva-mate em Mato Grosso do Sul. Revista em Agronegócio e Meio Ambiente, Maringá, v. 8, n. 1, p. 57-58, jan./abr. 2015. DOI: http://dx.doi. org/10.17765/2176-9168.2015v8n1p57-78. 